\title{
Tecnicidade como mediação estrutural no processo de trânsito das audiências: apontamentos para a comunicação organizacional contemporânea
}

Technicity as a structural mediation in the process of transit of audiences: notes for contemporary organizational communication

Tecnicidad como mediación estructural en el proceso de tránsito de las audiencias:apuntes para la comunicación organizacional contemporánea

\section{Mônica Pieniz}

- Doutora em Comunicação e Informação pela Universidade Federal do Rio Grande do Sul (UFRGS), com estágio de doutorado-sanduíche na Roskilde University da Dinamarca (RUC-DK)

- Mestre em Comunicação e graduada em Relações Públicas pela Universidade Federal de Santa Maria (UFSM)

- Professora adjunta do Departamento de Comunicação da Faculdade de Biblioteconomia

- $\quad$ e Comunicação (Fabico) da UFRGS

- Integrante do Observatório Ibero-americano de Ficção Televisiva (Obitel/RS)

- Pesquisadora nos grupos "Comunicação e práticas culturais" e "Comunicação organizacional, cultura e relações de poder"

- E-mail: monica.pieniz@ufrgs.br 


\section{Resumo}

Este artigo traz apontamentos para a comunicação organizacional, a partir da reflexão sobre elementos de uma tese de doutorado que objetivou compreender o processo de trânsito das audiências, onde receptores se tornam emissores ao compartilharem suas percepções sobre telenovela no Twitter. Os resultados evidenciaram conteúdos e motivações relacionados não somente à trama, mas a outros aspectos ligados à relação do público com a organização, o que mostra a necessidade de as organizações se tornarem receptoras e emissoras crossmidiáticas na relação com os diferentes públicos.

\section{PALAVRAS-CHAVE: TECNICIDADE• TRÂNSITO DAS AUDIÊNCIAS•CROSSMEDIA•COMUNICAÇÃO ORGANIZACIONAL CONTEMPORÂNEA.}

\section{Abstract}

This article provides notes for organizational communication using the reflection on elements of a doctoral thesis that aimed at understanding the process of audiences, where receivers become broadcasters when sharing their perceptions of soap operas on the Twitter. The results showed contents and motivations related not only to the plot, but other aspects of the public's relationship with the organization, showing the need for organizations to become cross-media receivers and broadcasters in relation to different audiences.

\section{KEYWORDS: TECHNICITY •TRANSIT OF THE AUDIENCES•CROSS-MEDIA •CONTEMPORARY ORGANIZATIONAL COMMUNICATION.}

\section{Resumen}

Este artículo proporciona apuntes para la comunicación organizacional, a partir de la reflexión sobre elementos de una tesis doctoral que tuvo como objetivo comprender el proceso de tránsito de las audiencias, donde receptores se convierten en transmisores al compartir sus percepciones acerca de telenovelas en el Twitter. Los resultados mostraron contenidos y motivaciones relacionadas no solamente con la trama, sino a otros aspectos vinculados a la relación del público con la organización, lo que muestra la necesidad de las organizaciones para convertirse en receptores y transmisores crossmediáticos en la relación con los diferentes públicos. 


\section{ANO 12 • NÚMERO $22 \cdot 1^{0}$ sem. 2015 - ORGANICOM TECNICIDADE COMO MEDIAÇÃO ESTRUTURAL NO PROCESSO DE TRÂNSITO DAS AUDIÊNCIAS: APONTAMENTOS PARA A COMUNICAÇÃO ORGANIZACIONAL CONTEMPORÂNEA}

$\mathrm{P}$ esquisar os públicos sempre foi um dos principais pilares para pensar na excelência (Grunig, 2011) das áreas de relações públicas e de comunicação organizacional. Na contemporaneidade, esta se torna uma demanda constante à medida que 0 acesso aos espaços digitais promove o comportamento desses públicos a um novo patamar de visibilidade - 0 que oferece às organizações um terreno fértil e de fácil acesso aos dados que aí circulam. Mobilizações sociais, críticas às organizações, expectativas quanto à realização de megaeventos ou a simples expressão lúdica sobre algum programa televisivo, por exemplo, pautam milhares de comentários nas mídias sociais.

Em nossas rotinas organizacionais, conforme Elizabeth S. Corrêa (2009), temos assistido a uma simbiose dos fluxos de informação e dos processos de comunicação de maneira gradativa e acelerada, fazendo-se deles um dos componentes mais estratégicos dos ambientes corporativos. Esse contexto reconfigura todas as dimensões da comunicação organizacional (Baldissera, 2009), especialmente pela ascensão de um público que se apropria das possibilidades de emissão propiciadas pela web, o qual Carolina Terra (2011) denomina usuário-mídia, e acaba por pressionar as organizações ao aprimoramento e à reconfiguração de suas formas de comunicação. Desse modo, pesquisas que possam investigar a recepção dessa comunicação organizacional na internet', e a diversidade de seus desdobramentos, tornam-se uma demanda constante para as organizações que buscam um posicionamento estratégico.

Sob essa perspectiva dos estudos de recepção, busca-se analisar neste artigo alguns dos resultados de nossa tese de doutorado (Pieniz, 2013), sobre manifestações na web provenientes de receptores de telenovela, ou seja, um segmento de público de uma organização midiática, o qual abrange a dimensão da organização falada (Baldissera, 2009). Diferentes metodologias podem ser utilizadas para analisar esses materiais provenientes dos públicos em espaços onde a organização não tem poder de administração. Por outro lado, a investigação da relação dos públicos com outros produtos e organizações, ou seja, uma pesquisa de recepção de outras formas de comunicação organizacional, poderia ser executada a partir das etapas a seguir descritas. A pesquisa aqui exposta, desse modo, se mostra como uma entre essas diferentes possibilidades. Por isso isso, explicita-se, na sequência, o objetivo da tese, o objeto empírico, os procedimentos metodológicos, o enfoque teórico, os resultados obtidos e, a partir destes, os apontamentos para a área de comunicação organizacional.

Compreender parte de um processo de trânsito das audiências, ${ }^{2}$ onde receptores se tornam emissores ao compartilharem suas percepções no Twitter ${ }^{3}$, foi o objetivo que guiou este estudo. A compreensão desse processo se deu a partir da investigação acerca das motivações ${ }^{4}$ e dos conteúdos envolvidos na prática de tuitar sobre telenovela da emissora Rede Globo. Esta escolha decorreu, entre outros motivos, da excelência desse produto no contexto brasileiro - pelas discussões sociais que suscita - e da relevância quantitativa das manifestações acerca desse assunto na rede social Twitter, o que pode dar bons indícios das práticas dos brasileiros frente a diferentes mídias, produtos e organizações.

0 objeto empírico, cujos registros e recortes foram acompanhados de observação, foi composto por tweets e respostas a questões de entrevistas. 0 protocolo metodológico partiu de uma inspiração etnográfica, com etapas on-line (Fragoso, Recuero e Amaral, 2011; Braga, 2008) e off-line, quantitativa e qualitativa. 0 corpus selecionado para a análise foi composto por um conjunto de mais de 35 mil tweets coletados durante o período de três anos, de 2010 a 2012, sendo 104 dias diferentes

1 Para compreender o panorama de pesquisas de recepção na internet, ver Mônica Pieniz e Laura Wottrich (2014).

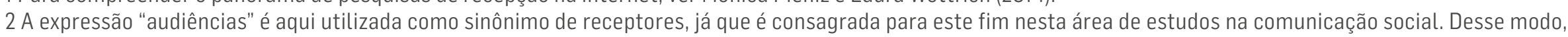

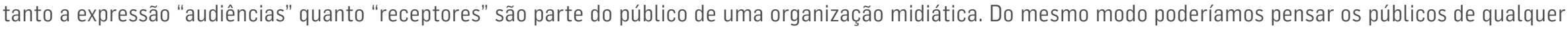
outra organização como audiência de suas respectivas estratégias de comunicação organizacional.

3 Disponível em: <http://Twitter.com/\#>. Acessado em: 10/02/2014.

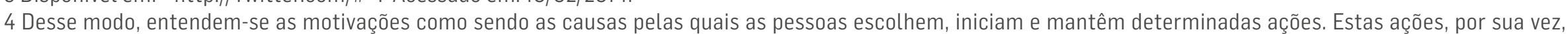

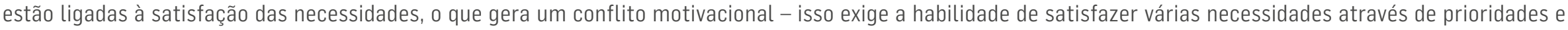
hierarquias, como as propostas por Abrahm Maslow, em 1943 (Blackwell; Miniard; Engel, 2008). 
de coletas, a partir das hashtags ${ }^{5}$ \#passione, \#insensatocoracao e \#finaestampa (Globo, 2010; 2011a; 2011b). Esse corpus foi inserido no software Nvivo10, onde foi submetido a uma análise de palavras mais frequentes, inspirada na análise de conteúdo (Bardin, 1979), a fim de verificar os conteúdos relevantes nesse conjunto de dados.

A partir desse material foram rastreados os tuiteiros mais atuantes, aos quais foram enviados convites para responder a um questionário on-line, somando sessenta retornos e, a partir destes, sete entrevistas de segunda etapa (Gil, 2008), entre 2012 e 2013 - duas presenciais, uma pelo Facebook, uma pelo Skype e três por e-mail). 0 material coletado com as respostas ao questionário e à entrevista permitiram a análise quanto às motivações envolvidas na prática de tuitar sobre telenovela, como também a caracterização dessa prática. Após a análise quantitativa e qualitativa das informações coletadas, foi possível descrever a caracterização de tais práticas utilizadas por esse público, à luz do objeto teórico a seguir.

\section{A TECNICIDADECOMO MEDIAÇÃO ESTRUTURAL E SUAS DERIVAÇÕES CONCEITUAIS}

Para fundamentar teoricamente esse cenário empírico, a discussão partiu, fundamentalmente, do conceito de mediação da tecnicidade, o qual é aqui desdobrado na convergência midiática (Jenkins, 2008) - no cenário de trânsito das audiências, como uma condição comunicacional contemporânea (Orozco Gómez, 2011) - e nos processos em vias de midiatização. Tendo em vista essa condição comunicacional contemporânea, compreende-se a midiatização, em suas diferentes abordagens - nos âmbitos micro, meso e macro - como uma das possíveis transformações em curso na convergência midiática. Tal desdobramento é posto como uma hierarquização conceitual onde a noção de tecnicidadeé relacionada com os demais conceitos e suas variações como a mediação estrutural da vida social, mas não a única. Parte-se do que explica Jesús Martín-Barbero (2010, p. 49):

É mesmo o lugar da cultura que muda na sociedade quando a mediação tecnológica da comunicação deixa de ser instrumental para tornar-se mais espessa, mais densa, e se converter em estrutural. Pois a tecnologia remete hoje não somente, e não tanto, à novidade dos aparatos, mas a novos modos de percepção e de linguagem, a novas sensibilidades e escrituras. (...) a tecnologia deslocaliza os saberes, modificando tanto o estatuto cognitivo como o institucional (...), o que está conduzindo a um forte borramento das fronteiras entre razão e imaginação, saber e informação, natureza e artifício, arte e ciência (...) (grifos do autor) .

Trata-se aqui, portanto, de analisar empiricamente essas novas sensibilidades, que partem das novas percepções, e verificar as novas escrituras nas diferentes formas de emissão de conteúdos, como parte das novas linguagens a partir do que se compreende da reflexão de Martín-Barbero (2010). 0 imbricamento entre essas dimensões gera um complexo cenário a ser analisado, pois todas essas emissões são retroestimuladas, umas pelas outras, ao mesmo tempo em que deixam rastros de acesso público, que podem ser registrados e armazenados. As novas sensibilidades estimulam motivações específicas para publicar diferentes conteúdos que precisam ser formatados dentro das possibilidades do meio, configurando e sendo configurado, então, por novas escrituras.

A tecnicidade é também entendida como a capacidade de inovação dos formatos industriais e das formas de receber mensagens midiáticas, é " menos assunto de aparatos do que de operadores perceptivos e destrezas discursivas" (MartínBarbero, 2008, p. 18). Aí também já temos indício da preocupação do autor com a convergência midiática, quando afirma: "a

5 Etiquetas demarcadoras de conteúdo no Twitter, as quais foram aqui utilizadas como filtros de pesquisa.

6 Tradução nossa. Original: "Es el lugar mismo de la cultura en la sociedad el que cambia cuando la mediación tecnológica de la comunicación deja de ser instrumental para espesarse, densificarse y convertirse em estructural. Pues la tecnología remite hoy no solo y no tanto a la novedad de los aparatos, sino a nuevos modos de percepción y de lenguaje, a nuevas sensibilidades y escrituras. (...) la tecnología deslocaliza los saberes modificando tanto el estatuto cognitivo como institucional (...), lo que está conduciendo a un fuerte borronamiento de las fronteras entre razón e imaginación, saber e información, naturaliza y artificio, arte y ciência (...)". 


\section{ANO 12 • NÚMERO $22 \cdot 1^{0}$ sem. 2015 - ORGANICOM TECNICIDADE COMO MEDIAÇÃO ESTRUTURAL NO PROCESSO DE TRÂNSITO DAS AUDIÊNCIAS: APONTAMENTOS PARA A COMUNICAÇÃO ORGANIZACIONAL CONTEMPORÂNEA}

estratégica mediação da tecnicidadese delineia atualmente em um novo cenário (...), não só no espaço das redes informáticas como também na conexão dos meios - televisão e telefone - com o computador" (Martín-Barbero, 2008, p. 19).

Preocupa-nos, a partir dessa mediação, o ponto de trânsito das audiências (Orozco Gómez, 2011), na prática que as torna também emissoras em um espaço da web, no cenário propiciado pela convergência midiática - a qual está engendrada no tecido social. Anterior e junto da comunicação digital, que permite os fluxos one-one, one-much e much-much, há a comunicação interpessoal, face a face, e a massiva (Jensen, 2010). Essas formas retomam o oral, perpassam o massivo e instituem uma nova forma de comunicar; onde antes os agentes tinham as limitações da comunicação comunitária, hoje têm seu próprio espaço midiático, com potencial de ativismo em maior escala, denúncia, ou simplesmente de entretenimento e socialidade - mas com certeza com poder de emissão além da sua rede social off-line.

A tentativa aqui empreendida está na direção desses estudos que veem no cerne do fenômeno o papel dos atores sociais, que afetam na mesma medida em que são afetados. Os públicos organizacionais, por exemplo, assumem, ou ao menos têm potencial para assumir, estratégias além de táticas (Certeau, 1994), reestruturando a atuação coletiva, os relacionamentos, a política e os direitos do consumidor. As relações com a mídia e com as organizações estão sofrendo mudanças através das alternativas ofertadas pela convergência, abrindo novos caminhos para os estudos de recepção da comunicação organizacional e da opinião sobre os seus produtos e serviços.

Conforme Henry Jenkins (2008), autor responsável pela popularização do termo, estamos realizando essa mudança por meio de nossas relações com o que é cotidiano, e as habilidades que adquirimos nessa prática têm implicações no modo como aprendemos, trabalhamos, participamos do processo político e nos conectamos com pessoas de outras partes do mundo. "A convergência das mídias é mais do que apenas uma mudança tecnológica. A convergência altera a relação entre tecnologias existentes, indústrias, mercados, gêneros" (Jenkins, 2008, p. 41). Inteligência coletiva, convergência e participação são parte da mesma realidade a partir da web.

Entretanto, ao falarmos de participação, a questão do acesso se amplia para além das tecnologias. A participação implica a reflexão acerca dos protocolos e das práticas culturais (Jenkins, 2008). Os atuais participantes dessas apropriações influenciam relevantemente a cultura midiática. As contendas e as conciliações resultantes do uso das tecnologias irão definir a cultura pública do futuro, hoje protagonizada prioritariamente por jovens. Estes compõem grande parte dos públicos que são ativos, migrantes, conectados socialmente, barulhentos e visíveis. "As promessas desse novo ambiente midiático provocam expectativas de um fluxo mais livre de ideias e conteúdos. Inspirados por esses ideais, os consumidores estão lutando pelo direito de participar mais plenamente de sua cultura" (Jenkins, 2008, p. 44) - o que demanda das organizações um estado vigilante para redefinir posturas e ações.

0 trânsito possível e desejável de receptores a produtores e emissores é talvez uma das mudanças sociais mais significativas da atualidade. É um trânsito de audiências espectadoras e receptivas, embora não irremediavelmente passivas (pelo menos não sempre) a audiências produtoras, embora não necessariamente criativas ou críticas (Orozco Goméz, 2011). Audiências inerentemente crossmidiáticas ${ }^{\top}$ (Schrøder, 2011) trazem novos desafios na era da internet - de audiências massivas para audiências interativas diante da convergência (Livingstone, 2003; 2004). E como uma possível consequência desse patamar da tecnicidade, inclui-se a sociedade em vias de midiatização.

7 A ideia de crossmídia refere-se à relação com diferentes meios de comunicação e aos seus cruzamentos, seja na emissão ou na recepção. Neste caso, audiências crossmidiáticas refere-se à recepção de conteúdos em diferentes meios de comunicação. 
Esse tema tem gerado, há muitos anos e em diferentes países, uma discussão em diferentes âmbitos, os quais estão aqui divididos, conforme Andreas Hepp (2011), em nível macro, meso e micro. Para esse autor, a midiatização tem se tornado um conceito-chave, porém o seu uso é questionado por ter tendência a uma compreensão linear e acrítica do processo de mudança que provoca na sociedade. Hepp sintetiza em três degraus o contexto norte-europeu de pesquisa acerca da midiatização, os quais são percebidos também na pesquisa nacional brasileira: o primeiro é sobre os momentos tecnológicos e institucionais dentro da pesquisa de midiatização, os quais abordam a lógica midiática; o segundo é a midiatização como um metaprocesso e um panorama, de longo prazo; e o terceiro é a análise a partir das forças de moldagem da mídia expressão que configura o seu pensamento quanto à midiatização.

Quantitativamente, para Hepp (2011), a midiatização implica mais tecnologias, meios e formas de apropriação, com mudanças no tempo, espaço, nível social e em interações. É um processo sinérgico de dispersão dos meios - o que iria ao encontro da ideia de convergência, já comentada. Qualitativamente, entretanto, há as forças de moldagem da mídia: quando a forma de comunicação muda com o meio, ou quando o meio muda em função das mudanças nas formas de comunicar/interagir. A mídia, conforme ele, exerce certa "pressão" na forma como comunicamos.

As forças de moldagem se concretizam em diferentes formas de comunicação. Existem especificidades em cada meio, as quais são produzidas pela ação humana em seus diferentes contextos - e, portanto, não são decorrentes somente da(s) lógica(s) midiática(s), mas das formas de apropriação dos espaços pelos públicos. Devem-se analisar as forças de moldagem dos meios sempre em sua rede de ação humana, comunicativa.

A especificidade dos meios só pode ser percebida no seu contexto de apropriação - o que vai ao encontro da ideia de mediações de Martín-Barbero. Hepp (2011) quer, portanto, investigar a relação entre as mudanças dos meios de comunicação e as mudanças socioculturais. Cada meio implica determinados poderes comunicativos atrelados às apropriações das forças de moldagem. Por isso, cada elemento social analisado exige uma construção teórico-metodológica específica.

OTwitter, por exemplo, apresenta certas peculiaridades, como a limitação de 140 caracteres por mensagem, a não-obrigatória reciprocidade entre seguir e ser seguido, a praticidade e objetividade do seu uso. Estas características constituem-se como forças que conformam certas práticas exclusivas para o público de uma emissora televisiva, por exemplo, como será explicitado no próximo item. A partir desse espaço empírico de investigação percebem-se as possibilidades materiais da convergência midiática e a mediação estrutural da tecnicidade que está latente nas práticas do público investigado.

\section{AS MOTIVAÇÕES E CONTEÚDOS ENVOLVIDOS NA PRÁTICA DO PÚBLICO TUITEIRO}

Guiados pelo enfoque teórico da mediação da tecnicidade, os resultados (Pieniz, 2013) da análise do objeto empírico apontaram para três esferas principais de conteúdos nos tweets: a) ligados à trama (com mais de 16 mil incidências em 103 dias diferentes de coleta, considerando palavras relacionadas a nomes de personagens e a temas da trama, por exemplo); b) relacionados à visão de telenovela como um produto midiático (com mais de 5 mil incidências em 103 dias de coleta, quando presentes expressões sobre a trilha sonora, aspectos da produção, nome dos atores, índices de audiência, por exemplo); c) voltados para ações do cotidiano dos receptores (com mais de 5 mil incidências em 103 dias de coleta, somadas as palavras jantar, banho, assistindo, por exemplo). 
Isso demonstra que a ação de comentar sobre telenovela no Twitter gera comentários que refletem o engajamento não somente com a trama, mas também com os aspectos mercadológicos ligados à emissora, e ainda a relação do produto com o cotidiano dos tuiteiro. Semelhantemente ocorre com os resultados quanto às motivações, que são os fatores que levam à pratica de tuitar, as quais referem-se à relação com a telenovela, a partir da perspectiva da trama ou do produto midiático, mas também à relação com o próprio Twitter, diante da possibilidade de expressão, interação e busca por popularidade.

Além de ser o que na pesquisa se denominou "recepção compartilhada na web"8, esta é uma prática de sujeitos que, ao mesmo tempo em que são parte de uma audiência - de um público - buscam atender à sua própria "possível" audiência seu próprio público, no Twitter. Este é um fator crucial para análise na área de relações públicas, uma vez que temáticas suscitadas por organizações tornam-se pretexto de comentários que têm como objetivos gerar interações mútuas (neste caso, por exemplo: replies) e reativas (por exemplo: retweets e indicação de tweet favorito), de acordo com Alex Primo (2008), e não somente a emissão, em si.

0 trânsito das audiências, percebido por Orozco Gómez (2011), é aqui esmiuçado em seus diferentes trajetos. Os dados mostraram que o movimento do trânsito não consiste somente em ser emissor e receptor, mas também nos diferentes fluxos de recepção e de emissão. 0 caráter inerentemente crossmidiático das audiências se mostra aqui, a partir dos dados empíricos, tanto em mídias tradicionais como em espaços on-line de mídias sociais.

Especificamente, os receptores ficam sabendo sobre a trama a partir da assistência da telenovela pela televisão, pelo site da Globo ou mesmo pelo Youtube. Além disso, eles leem revistas, acessam blogs e outros sites especializados no tema e também leem tweets dos demais receptores tuiteiros, como, também, ficam sabendo de algumas novidades pelos amigos ou familiares. Há, portanto, um caráter crossmidiático no processo de recepção, o qual envolve espaços de mídias tradicionais ou não, on-line ou off-line.

0 mesmo ocorre em relação à emissão. Blogs, fóruns e outras redes sociais on-line além do Twitter podem ser acessados para fins de emissão de comentários. A emissão, portanto, pode ser igualmente crossmidiática. Junto disso o tuiteiro pode ser emissor do que recebeu pelo Twitter para seu âmbito de relações off-line. 0 trânsito das audiências, tanto dentro das diversas possibilidades de receber quanto de emitir conteúdos, e ainda quanto a intercalar os papeis de emissão e recepção, é contínuo e retroalimentado. Os resultados sinérgicos de cada ciclo se refletem no começo de um novo ciclo, conformando novas ritualidades e socialidades no cotidiano dos tuiteiros.

Os resultados aqui alcançados estão circunscritos, obviamente, num tempo e espaço determinados e delimitados. Entretanto, por serem uma mostra de relações numa parte do real, podem servir de base para compreender as tendências de apropriações tecnológicas por parte dos públicos, para além do Twitter e de um produto específico como a telenovela. Esses aspectos contemplam uma complexa trama de diferentes características analisadas pelo público na relação com a organização.

\section{CONSIDERAÇÕES FINAIS}

A partir do que expusemos até aqui, façamos alguns apontamentos e algumas considerações para a comunicação organizacional contemporânea.

8 A expressão "compartilhada" é aqui utilizada no sentido de expressar, emitir, dividir, com certa dimensão "pública", aberta, manifesta na web. Entende-se aqui a web como parte da internet e as redes sociais on-line como parte da web. Já as redes sociais off-line se referem ao círculo de convívio cotidiano, além e aquém da web, o que envolve relações presenciais, face a face. 
A compreensão sobre parte do trânsito das audiências empreendida nesta pesquisa permite a reflexão sobre o ponto de vista dos públicos crossmidiáticos em relação a produtos e à organização - o que evidencia as possibilidades para a reconfiguração da comunicação organizacional diante da mediação estrutural da tecnicidade. Nos amplos espaços de conversação permitidos pelas mídias sociais (Recuero, 2012) - o que serve para qualquer tipo de organização e não somente para as midiáticas -, os públicos potencializam o seu poder de engajamento e crítica a causas, a marcas e à postura das organizações.

Mesmo não tendo controle sobre o que falam os públicos, na dimensão da organização falada (Baldissera, 2009), os gestores da comunicação organizacional podem ter fácil acesso a suas manifestações. Com isso é possível gerar insumos que podem ser processados para o conhecimento organizacional e a reelaboração de estratégias de aproximação, a partir de um monitoramento e uma análise constantes - contemplando assim, as dimensões da organização comunicada e comunicante (Baldissera, 2009). Saber gerenciar essas informações, as quais podem se manifestar em grande volume, como o chamado big data, pode ser fator decisivo quando se trata de imagem e reputação organizacional. Nesse ponto, o olhar do relações-públicas como analista de cenários (Ferrari, 2011) se faz fundamental, pensando em espaços on-line e off-line, concomitantemente.

Além disso, os assuntos que dizem respeito às organizações tornam-se pautas para os sujeitos alimentarem os seus próprios espaços midiáticos, a partir das quais podem ganhar popularidade e visibilidade no âmbito das redes sociais on-line, seja por questão de status atribuído ao consumo de determinado produto ou por se tornarem referência ao compartilharem suas opiniões. Os envolvidos nessa rede, ao comentarem e compartilharem, geram um fluxo contínuo de conteúdos, os quais podem contemplar instigantes conversações (Recuero, 2012), evidenciando os desafios desse cenário que se retroalimenta. Por isso, é urgente testar e aprimorar estratégias metodológicas de pesquisa diante dessas informações circulantes que acabam por interferir, positiva ou negativamente, no andamento das organizações.

A figura a seguir, busca ilustrar esse cenário de mediação estrutural da tecnicidade na comunicação organizacional. Há uma intercalação constante (número 3 na figura) dos papéis de emissão (1) e recepção (2), em diferentes meios.

Figura 1 - Mediação estrutural da tecnicidade na comunicação organizacional

\section{MEDIAÇÃO ESTRUTURAL DA TECNICIDADE (MARTIN-BARBERO, 2010) NA COMUNICAÇÃO ORGANIZACIONAL}

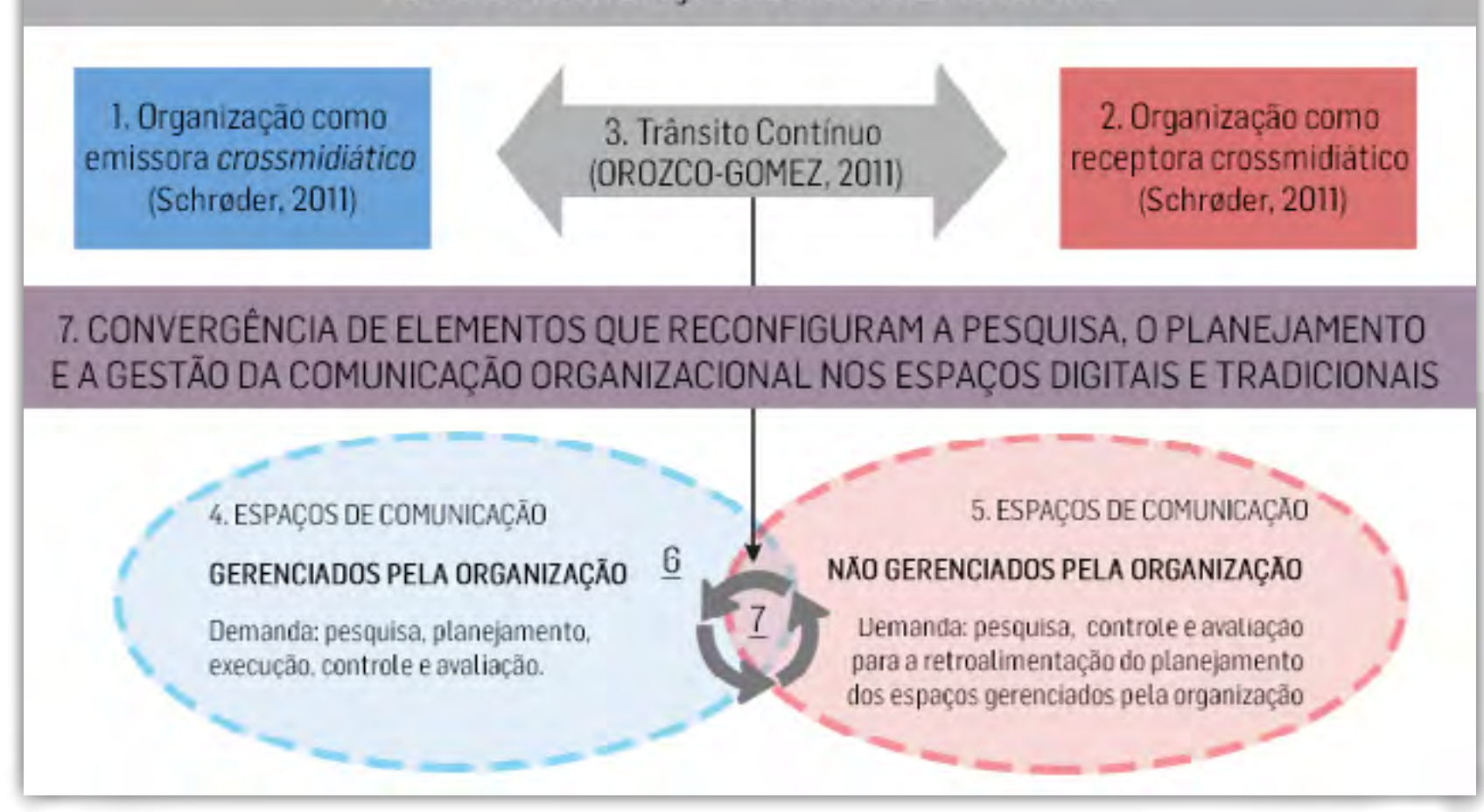

Fonte: elaborada pela autora. 
À medida que as organizações se interessam por um posicionamento estratégico, podem buscar monitorar as informações (6) que circulam em espaços não passíveis de seu gerenciamento (5) e, a partir disso, usá-las como insumos para retroalimentar suas bases de dados e readequar o planejamento de seus espaços de comunicação (4). Essa forma de convergência (7) de elementos reconfigura a comunicação organizacional, pois gera a demanda de realinhamento constante das estratégias de comunicação tradicionais e digitais a fim de dar conta de atender aos diferentes públicos de forma excelente (Grunig, 2011), melhorando os relacionamentos.

Os resultados da pesquisa sobre o trânsito nas ações das audiências, portanto, fazem-nos atentar para a necessidade do trânsito nas posturas das organizações frente aos seus públicos. Há possibilidade, mais que nunca, das organizações se comportarem como verdadeiras receptoras crossmidiáticas das reinvindicações dos seus públicos, tanto nos seus espaços oficias de comunicação na web - naqueles onde detêm o controle da emissão - como nos espaços que não são de sua administração. A mediação estrutural da tecnicidade, dessa forma, é sentida na realidade organizacional, dentre outros espaços sociais, e traz a necessidade de pesquisas empíricas da recepção da comunicação organizacional para expandir e aprofundar as reflexões acerca desse cenário.

\section{REFERÊNCIAS}

BARDIN, L. Análise de conteúdo. Lisboa: Edições 70, 1979.

BALDISSERA, R. Comunicação oganizacional na pespectiva da complexidade. Organicom-Revista Brasileira de Comunicação Organizacional e Relações Públicas, a. 6, n. 10/1, São Paulo, Gestcorp/ECA-USP, p.115-120, 2009.

BLACKWELL, R. D.; MINIARD, P. W.; ENGEL, J. F. Comportamento do consumidor. 8. ed. Rio de Janeiro: S. A., 2008.

BRAGA, A. Personas materno-eletrônicas: feminilidade e interação no blog Mothern. Porto Alegre: Sulina, 2008.

CERTEAU, M. de. A invenção do cotidiano: artes de fazer. Petrópolis, RJ: Vozes, 1994.

CORREAA, E. S. Comunicação digital e novas mídias institucionais. In: KUNSCH, M. M. K. Comunicação organizacional. Vol. 1. Histórico, fundamentos e processos. São Paulo: Saraiva, 2009.

FERRARI, M. A. A prática de relações públicas no cenário latino-americano. In: GRUNIG, J.; FERRARI, M. A.; FRANÇA, F. Relações públicas: teoria, contexto e relacionamentos. São Caetano do Sul, SP: Difusão, 2011.

FRAGOSO, S.; RECUERO, R.; AMARAL, A. Métodos de pesquisa para internet. Porto Alegre: Sulina, 2011.

GIL, A. Métodos e técnicas de pesquisa social. São Paulo: Atlas, 2008.

GLOBO, Rede. Fina estampa. [Telenovela]. Brasil, 2011a. Insensato coração. [Telenovela]. Brasil, 2011b.

Passione. [Telenovela]. Brasil, 2010. 
GRUNIG, J. Definição e posicionamento das relações públicas. In: GRUNIG, J.; FERRARI, M. A.; FRANÇA, F. Relações públicas: teoria, contexto e relacionamentos. São Caetano do Sul, SP: Difusão, 2011.

HEPP, Andreas. Mediatization, media technologies and the 'moulding forces' of the media. In: INTERNATIONAL COMMUNICATION ASSOCIATION ANNUAL CONFERENCE, 2011. Annals... Boston: ICA, 2011.

JENKINS, H. Cultura da convergência. São Paulo: Aleph, 2008.

JENSEN, K. B. Media convergence: the three degrees of network, mass, and interpersonal communication. Routledge: new York, 2010.

LIVINGSTONE, S. The challenge of changing the audiences: or, what is the researcher to do in the age of the internet? London Research on-line, 2004. Disponível em: <http://eprints.lse.ac.uk/412/1/Challenge_of_changing_audiences_-spoken_version.pdf>. Acesso em: 05 jul. 2012.

From the mass audience to the interactive media user. London Research on-line, 2003, p. 19-38. Disponível em: <http://eprints.lse.ac.uk/417/1/Chapter_in_Valdivia_Blackwell_volume_2003.pdf>. Acesso em: 05 jul. 2012.

MARTÍN-BARBERO, J. Dos meios às mediações: comunicação, cultura e hegemonia. 5. ed. Rio de Janeiro: UERJ, 2008.

. Convergencia digital y diversidade cultural. In: MORAES, D. de. Mutaciones de lo visible: communicación y processos culturales en la era digital. Buenos Aires: Paidós, 2010.

OROZCO GÓMEZ, G. La condición comunicacional contemporânea: desafíos latino-americanos de la investigación de las interaciones en la sociedade red. In: JACKS, N. (Coord.). Análisis de recepción en América Latina: un recuento histórico con perspectivas al futuro. Quito: Ciespal, 2011.

PIENIZ, Mônica. Tecnicidade como mediação empírica: a reconfiguração da recepção de telenovela a partir do Twitter. Tese (Doutorado em Comunicação e Informação) - Universidade Federal do Rio Grande do Sul, 2013. Disponível em: <http://hdl. handle.net/10183/76995>. Acesso em: 15.06.15.

PIENIZ, Mônica; WOTTRICH, Laura. Receptores na internet: desafios para o contexto de trânsito das audiências. In: JACKS, Nilda (Org.). Meios e Audiências Il: a consolidação dos estudos de recepção no Brasil. Porto Alegre: Sulina, 2014.

PRIMO, Alex. Interação mediada por computador. Porto Alegre: Sulina, 2008.

RECUERO, Raquel. A conversação em rede: comunicação mediada por computador e redes sociais na internet. Porto Alegre: Sulina, 2012.

SCHRØDER, K. C. Audiences are inherently cross-media: audience studies and the cross-media challenge, 2011. On-line. Disponível em: <http://www.fpn.bg.ac.rs/wp-content/uploads/CM18-Web.pdf>. Acesso em: 10 mar. 2013.

TERRA, C. F. Mídias sociais... E agora? O que você precisa saber para implementar um projeto de mídias sociais. São Caetano do Sul, SP: Difusão; Rio de Janeiro: Editora Senac, 2011. 